\title{
DIFFERENCES IN CITATION PATTERNS ACROSS JOURNAL TIERS IN ECONOMICS
}

\author{
María Victoria Anauati \\ Sebastian Galiani \\ Ramiro H. Gálvez
}

\section{LATIN AMERICAN AND THE CARIBBEAN ECONOMIC ASSOCIATION}

September 2018

The views expressed herein are those of the authors and do not necessarily reflect the views of the Latin American and the Caribbean Economic Association. Research published in this series may include views on policy, but LACEA takes no institutional policy positions.

LACEA working papers are circulated for discussion and comment purposes. Citation of such a paper should account for its provisional character. A revised version may be available directly from the author.

(C) 2018 by María Victoria Anauati, Sebastian Galiani and Ramiro H. Gálvez. All rights reserved. Short sections of text, not to exceed two paragraphs, may be quoted without explicit permission provided that full credit, including (C) notice, is given to the source. 
LACEA WORKING PAPER SERIES No. 0012 September 2018

Differences in citation patterns across journal tiers in economics

\author{
María Victoria Anauati \\ Ministry of Treasury, Argentina \\ victoria.anauati@gmail.com
}

Sebastian Galiani

University of Maryland and NBER

Galiani@econ.umd.edu

Ramiro H. Gálvez

Universidad de Buenos Aires

ramirogalvez@gmail.com

\begin{abstract}
Economics places a strong emphasis on publishing in a narrow set of top tier journals. Given that venue reputation does not necessarily go hand in hand with citation performance, we study how citation patterns differ across journal tiers (top five, second tier, and top field). By analyzing citations of 6,083 articles, we find that citation patterns effectively vary greatly across tiers, affecting not only articles' total citations but also their distribution through time (i.e., their life cycles). Moreover, the way patterns differ across tiers is strongly associated to articles' success (measured by citation counts) and fields of economics research.
\end{abstract}

JEL Classification: A14

Keywords: citation analysis, journals tiers, fields of economics research. 


\title{
Differences in citation patterns across journal tiers in economics
}

\author{
María Victoria Anauati \\ Ministry of Treasury, Argentina \\ Sebastian Galiani \\ University of Maryland and NBER \\ Ramiro H. Gálvez \\ Universidad de Buenos Aires
}

\section{September, 2018}

\begin{abstract}
Economics places a strong emphasis on publishing in a narrow set of top tier journals. Given that venue reputation does not necessarily go hand in hand with citation performance, we study how citation patterns differ across journal tiers (top five, second tier, and top field). By analyzing citations of 6,083 articles, we find that citation patterns effectively vary greatly across tiers, affecting not only articles' total citations but also their distribution through time (i.e., their life cycles). Moreover, the way patterns differ across tiers is strongly associated to articles' success (measured by citation counts) and fields of economics research.
\end{abstract}

JEL: A14

Keywords: citation analysis, journals tiers, fields of economics research.

\section{Introduction}

Economics scholars place a strong emphasis on publishing in a narrow set of top general research journals (see, for example, Gibson, 2014; McKenzie, 2014), a trend which seems to have deepened in the last decades (Card and DellaVigna, 2013). Annual submissions to top five economics journals (i.e., the American Economic Review (AER), Econometrica (ECA), the Journal of Political Economy (JPE), the Quarterly Journal of Economics (QJE), and the Review of Economic Studies (RES)) nearly doubled from 1990 to 2012; however, since the total number of articles published in these journals actually declined, publishing in these journals has been reported to become harder and much slower (Card and DellaVigna, 2013). This emphasis in top five outlets has been shown to have a powerful influence on the direction of research in economics, the career paths of young researchers, the reputation and pay of economics scholars, the decision of funding agencies, as well as on the rankings of departments and universities (Hamermesh, 2018; Serrano, 2018; Gibson, Anderson, and Tressler, 
2017; Gibson, Anderson, and Tressler, 2014; Ellison, 2010; Smith and Eysenck, 2002; Cole and Cole, 1967; Hilmer and Hilmer, 2005; Oswald, 2007; Hilmer et al., 2011; Hamermesh and Pfann, 2012; Verma, 2015; Heckman and Moktan, 2017; Zimmermann, 2013; Hazelkorn, 2011).

Another strategy commonly used to assess researchers and research institutions performance is to count citations received by articles of their authorship/members (or, alternatively, use metrics which take citation counts as input) (see, for example, Cole and Cole, 1967; Ellison, 2013; Gibson, Anderson, and Tressler, 2017; Gibson, Anderson, and Tressler, 2014; Hazelkorn, 2015). However, exceling performance in terms of citations does not necessarily go hand in hand with publication venue reputation. An example may be illustrative: a top tier economics journal may focus its articles on theory or econometric methods papers, while a second tier or top field one may focus its articles on applied ones; as applied papers have been shown to receive, in general, more citations than theory and econometric methods ones (see Anauati, Galiani and Gálvez, 2016), the second tier journal could end up surpassing the top tier one in terms of citation performance.

To better understand the relation between these two strategies for assessing researchers' performance, empirical evidence quantifying and characterizing how journal tiers relate with citation performance in needed. In this article we delve into this issue. Concretely, we do this by providing answers to the following questions: Do total received citations differ between articles published in top five and well respected non-top five economics journal (i.e., second tier and top field journals)? Do the dynamics of received citations (i.e., life cycles) differ across journal tiers? ${ }^{1}$ If differences are to be found, do they vary across articles' levels of success (as measured by citation counts)? In other words, is a highly/slightly cited article published in a non-top five journal more or less similar (in terms of received citation) to one published in a top five journal? Moreover, are patterns similar or different across fields of economics research (i.e., applied, applied theory, econometric methods, and theory articles)?

To this end, we constructed a dataset containing detailed citation and articles' characteristics data. We do this by first listing all research articles published between 1992 and 1996 in the top five economics journals, a sample of second-tier general interest journals and a sample of top field journals. We then collect data on how yearly received citations evolved as they grew older. Finally, we classified each article into one of four fields of economics research (theory, applied research,

\footnotetext{
${ }^{1}$ Note that, as bibliometric indices usually restrict the range of articles that they use as input on the basis of the number of years that have passed since their publication, annual trends in citations may strongly influence the values of these indices.
} 
applied theory and econometric methods). Our main result is that citation patterns effectively vary greatly across journal tiers, affecting not only their total received citations but also how citations are distributed as articles grow older (i.e., along their life cycle) (e.g., yearly citations of median articles published in non-top five journals reach a lower peak and earlier in time than that of top five journals, suggesting the life cycle of the former is shorter). In line with previous literature, we find a relative overlap in total citations (i.e., the less highly-cited articles in the top journals are easily bettered by median articles in less prestigious outlets). Moreover, and we believe more importantly, we find that the way citation patterns differ across journals tiers is strongly associated to articles' success (as measured by citation counts) and field of economics research (e.g. not only the difference in total citations received by articles published in top five against non-top five journals are smaller for econometric methods papers, but also this gap narrows sharply as one moves toward more successful articles). In fact, we also show associations between citation patterns and the interaction between articles' success and field of research (e.g., in all fields of economics research, except for theory, the more successful a top five article is, the relatively less successful it is when compared to an equivalent article published in non-top five venues; but, for theory papers, the opposite pattern is observed: successful top five articles are even relatively more successful when compared to non-top five ones).

This paper contributes to a growing body of literature on quantitative economics that address the relevant papers' characteristics, their citation performance and the journals' decisions about what to publish. To the best of our knowledge, our paper is the first to analyze the heterogeneity in citation patterns across journal tiers considering articles' level of success and fields of economics research. In general, most of the literature has focused on top five journals leaving out second tier and field journals and/or ignoring the methodology used by articles. For instance, in terms of the publishing process, it has been documented that it has slowed down in top five journals (Ellison, 2002; Coe and Weinstock 1967; Yohe, 1980; Laband et al. 1990; and Trivedi, 1993) mainly due to lower acceptance rates and longer delays. In relation to citation performance and fields of economics research, Anauati, Galiani and Gálvez (2016) characterize how life cycle in yearly citations differ across fields of economic research in top five journals, finding strong differences in citation patterns across fields of economics research. Galiani and Gálvez (2017) find evidence that points to the presence of life-cycle patterns in annual citations that vary greatly across a broad range of scientific disciplines. Chiappori and Levitt (2003) use data on all empirical microeconomics papers published in AER, JPE and QJE over 1999 and 2001 to assess whether theoretical economic research succeeds in influencing the path of empirical microeconomics research. They find that theoretical papers cited as a primary motivation 
for empirical research projects are surprisingly dispersed; with very few theoretical papers having much of an influence on applied microeconomics papers.

The most closely related papers focusing on how citation varies across economic journals are those of Hammermesh (2018), Oswald (2007), and Stern (2013). Using a sample of 230 articles published in top five journals, Economic Journal and the Review of Economics and Statistics in 2007-2008, Hammermesh (2018) finds there is substantial overlap in citations (adjusted for its length) between these journals: many articles in these two second-tier general interest journals are cited more than the majority of articles published in the top five journals. According to this author, this in mainly because a very few papers in top journals generate immensely more citations than other papers published in those journals or elsewhere. Therefore, a very few outliers determine our perceptions of journal quality, perceptions that ignore the great heterogeneity of articles within and across journals. Oswald (2007) uses data on the accumulated lifetime citations over twenty-five years to papers published in 1981 in issues of the AER, ECA, Journal of Public Economics, Economic Journal, Journal of Industrial Economics, and the Oxford Bulletin of Economics and Statistics. He finds that the variation in the quality of journals, as measured by cites, is strikingly large. He reports that the more highlycited articles in good-to-medium quality journals has 10 times the citations impact of the slightly cited articles published in the top journals, but the less highly cited articles in the top journals are easily bettered by good articles in less prestigious outlets. Oswald (2007) also highlights there is a noticeably imperfect match between the quality of the journal and the lifetime cites of individual articles: 16 percent of articles in the four lesser journals he studied ended the period with more citations than the median cites of an article in the AER or ECA. Stern (2013) studies uncertainty associated with citations-based rankings by computing the standard error of impact factors for every economics journals with a five-year impact factor in the 2011 Journal Citations Report. He finds that the impact factors of the top two journals are well defined, and that an elite group of 9-11 mainstream journals can be fairly reliably distinguished. Additionally, he reports that the four bottom ranked journals are also fairly clearly set apart. Our paper differs from these articles in that it uses a fine-grained dataset including yearly citations to more than 6000 articles from top five, second tier general interest and top field journals. This allows us the study of heterogeneity in citation patterns systematically not only among different journals tiers, but also along their life cycles, across different levels of success, and across different fields of economics research.

The rest of this paper is organized as follows: Section 2 describes how we built our dataset. Section 3 covers our empirical analysis and main results. Section 4 provides discussion and concludes. 


\section{Data}

As a first step for constructing our dataset, we selected a set of journals to include into each tier under analysis (i.e., top five, prestigious second tier and top field tiers). Although, there is a consensus regarding which journals are considered top five journals (i.e., AER, ECA, JPE, QJE, and RES), classifying journals into second tier or top field tiers is more subjective. As second tier general research journals we included a sample of well-respected journals publishing articles covering general research topics; concretely, our sample of second tier journals includes the Economic Journal, Economic Inquiry, the European Economic Review, the Journal of Economic Literature (JEL), the Journal of Economic Perspectives (JEP), the International Economic Review, and the Review of Economics and Statistics. As top field journals we included a sample of well-respected journals known for focusing in one particular area of research; concretely our sample of top field journals includes the Journal of Development Economics, the Journal of Econometrics, the Journal of Economic Behavior and Organization, the Journal of Economic Theory, the Journal of Health Economics, the Journal of International Economics, the Journal of Labor Economics, the Journal of Law and Economics, the Journal of Monetary Economics, the Journal of Public Economics, the Journal of Urban Economics, and the RAND Journal of Economics.

Once these journals were chosen, from EconLit we listed all articles published in each of them from 1992 to 1996, and gathered their title, the name(s) of their author(s), their JEL codes and their publication information (pages, journal's name and volume). Based on both the title of the paper and subsequent checks, we excluded articles we identified as comments/replies, addresses/speeches and corrections. Like Card and DellaVigna (2013), we also excluded articles in the Papers and Proceedings of the AER. This left us with a final dataset of 6083 full-length refereed articles. Then, from Google Scholar, we collected detailed data on citations received by each article from two years before publication - to capture citations to preprints - up to and including twenty years since its publication. We refer as "total citations" received by an article to the sum of yearly citations received by and article during this time span covering 23 years. Data was retrieved from the end of March 2017 to the end of May 2017 using web crawling and natural language processing techniques. For roughly $9.7 \%$ of all articles, citation data could not be identified by automatic means. In these cases, the identification was done manually, and web crawling techniques were used to collect the data. Further details can be found in Anauati, Galiani and Gálvez (2016). A few citations of articles in Google Scholar do not have a timestamp attached to them; we noted that these citations tend to have a low impact (i.e., they are associated with a null citation count or non-formal scholarly documents), and we therefore decided to ignore the small subset of citations which do not have a timestamp. 
Finally, as in Hamermesh (2013) and Anauati, Galiani and Gálvez (2016), the field of research corresponding to each paper was identified by skimming each paper. As in Anauati, Galiani and Gálvez (2016), we classified each article into one and only one of the following research fields: applied, applied theory, econometric methods and theory. Figure A1 plots the distribution of fields of economics research across journals.

The criteria used to assign a paper to a category are as follows: 1) Applied papers are papers that have an empirical or applied motivation. They rely on the use of econometric or statistical methods as a basis for analyzing empirical data, although they may deal with simple models that serve as a theoretical framework for the analysis. This category also includes papers which do not use sophisticated econometric methods, but do use descriptive statistics to analyze, for example, given features of an economy and in which the empirical section figures as the central element. 2) Applied theory papers develop a theoretical model to explain a fact; the empirical analysis is not the most important feature of the paper, but a supplement. In these papers, the use of econometric or statistical analyses is limited, although they may use simulations (even with empirical data) or refine other techniques to test the implications of the models. 3) Econometric methods papers are articles that develop econometric or statistical methodologies. They also include papers that develop methodologies for collecting data and that address issues of identification, data aggregation or optimization techniques. 4) Theory papers do not contain an empirical fact section; they usually approach a topic by modeling and by making extensive use of formal mathematics and logic. They may include a numerical example or a simple model calibration with theoretical data to illustrate the proposed model or analyze its comparative statics. Further information on the way in which we have classified papers into these four categories can be found in Anauati, Galiani and Gálvez (2016).

\section{Characterizing citation patterns across journal tiers in economics}

Before analyzing detailed citation patterns, Table 1 reports summary statistics at the article level considering their total received citations across tiers and fields of economics research (Table S1 reports this data across journals). In top five journals, total citations per article range from 0 to 10836 , with a mean (median) of 491 (217) and 1815 citations at the $95^{\text {th }}$ percentile. For second tier journal papers, total citations range from 0 to 5741, with a mean (median) of 147 (51) and 651 citations at the $95^{\text {th }}$ percentile. The statistics describing the distribution of citations of top field journals papers are strikingly similar to second tier journal ones, with total citations ranging from 0 to 8676 and a mean (median) of $136(51)$ and 491 citations at the $95^{\text {th }}$ percentile. From comparing mean and median values, it can be seen that the skewness in the distribution of total citation at the article level is 
noteworthy. ${ }^{2}$ Additionally, this table already suggests that citation patterns differ greatly across fields of economics research, no matter the journal tier being analyzed.

Table 1. Summary Statistics of Total Citation at the Article Level across Journals Tiers and Fields of Economics Research

\begin{tabular}{|c|c|c|c|c|c|c|c|c|c|c|}
\hline Journal Tier & Research Field & $\begin{array}{c}\text { Percentil } \\
0.05\end{array}$ & Median & $\begin{array}{c}\text { Percentil } \\
0.75\end{array}$ & $\begin{array}{c}\text { Percentil } \\
0.95\end{array}$ & Mean & S.D. & $\begin{array}{l}\text { Most } \\
\text { cited }\end{array}$ & $\begin{array}{c}\text { Total } \\
\text { citations }\end{array}$ & $\begin{array}{l}\mathrm{N}^{\circ} \text { of } \\
\text { Articles }\end{array}$ \\
\hline \multirow[t]{5}{*}{ Top five } & Applied & 36.00 & 332.00 & 670.50 & $1,932.90$ & 609.65 & $1,012.69$ & 10,836 & 273,122 & 448 \\
\hline & Applied theory & 43.70 & 266.00 & 741.50 & $2,410.90$ & 604.66 & 851.16 & 4,539 & 96,141 & 159 \\
\hline & Econometric methods & 19.60 & 178.00 & 413.25 & $2,062.05$ & 432.32 & 734.80 & 5,131 & 49,285 & 114 \\
\hline & Theory & 13.70 & 156.00 & 451.50 & $1,325.40$ & 381.74 & 623.48 & 6,418 & 227,133 & 595 \\
\hline & All fields & 19.00 & 217.00 & 573.75 & $1,815.50$ & 490.64 & 818.35 & 10,836 & 645,681 & 1,316 \\
\hline \multirow[t]{5}{*}{ Second tier } & Applied & 6.00 & 66.00 & 151.75 & 733.05 & 180.81 & 386.16 & 5,741 & 172,496 & 954 \\
\hline & Applied theory & 4.55 & 54.00 & 158.50 & 684.85 & 168.30 & 331.26 & 3,187 & 35,680 & 212 \\
\hline & Econometric methods & 3.00 & 41.50 & 120.25 & 393.95 & 103.35 & 168.04 & 1,030 & 12,609 & 122 \\
\hline & Theory & 4.00 & 36.00 & 74.00 & 377.05 & 92.95 & 206.48 & 1,921 & 53,909 & 580 \\
\hline & All fields & 5.00 & 51.00 & 125.25 & 651.25 & 147.05 & 324.40 & 5,741 & 274,694 & 1,868 \\
\hline \multirow[t]{5}{*}{ Top field } & Applied & 8.00 & 80.00 & 187.25 & 584.50 & 169.48 & 289.44 & 3,504 & 160,328 & 946 \\
\hline & Applied theory & 5.25 & 52.50 & 137.75 & 527.25 & 133.99 & 269.25 & 2,899 & 38,321 & 286 \\
\hline & Econometric methods & 3.00 & 57.00 & 159.00 & 984.60 & 228.84 & 674.22 & 8,676 & 90,848 & 397 \\
\hline & Theory & 3.00 & 37.00 & 91.00 & 298.55 & 81.45 & 151.38 & 2,467 & 103,442 & 1,270 \\
\hline & All fields & 4.00 & 51.00 & 131.50 & 491.20 & 135.54 & 330.83 & 8,676 & 392,939 & 2,899 \\
\hline \multirow[t]{5}{*}{ All tiers } & Applied & 9.00 & 95.00 & 251.00 & $1,016.40$ & 258.07 & 564.61 & 10,836 & 605,946 & 2,348 \\
\hline & Applied theory & 6.00 & 73.00 & 252.00 & $1,067.00$ & 258.97 & 528.88 & 4,539 & 170,142 & 657 \\
\hline & Econometric methods & 4.00 & 65.00 & 188.00 & 972.60 & 241.30 & 630.18 & 8,676 & 152,742 & 633 \\
\hline & Theory & 4.00 & 47.00 & 130.00 & 702.40 & 157.25 & 364.29 & 6,418 & 384,484 & 2,445 \\
\hline & All fields & 5.00 & 67.00 & 186.00 & 893.00 & 215.90 & 500.12 & 10,836 & $1,313,314$ & 6,083 \\
\hline
\end{tabular}

To better understand time-dynamics of received citations, Figure 1 plots the evolution of average and median yearly citations, as well as articles' individual yearly citations trajectories, for every year since two years before its publication, discriminating by journal tier and field of economics research. ${ }^{3}$ First, in line with Table 1, it is clear that for every year average and median yearly citations of top five journal papers are higher than those of second tier and top field journals papers. In the first two years before the date of publication (i.e. years -2 and -1 ), the average citations of top journals papers almost doubles the average citations of second tier and field journals papers. This difference becomes bigger as time passes: after 15 years since publication the average citations of top journals papers is around four times the average citations of second tier and top field journals papers, suggesting a better maturity for top five papers. Second, life cycles differ across journal tiers. Notably, even without accounting for citation inflation, our data suggests that peaks in yearly citations are not reached at the

\footnotetext{
${ }^{2}$ Skewness in distribution of citation counts has been also reported in Card and DellaVigna (2013), Oswald (2007), Hamermesh (2018), among others.

${ }^{3}$ Concretely, being cit $_{i, t}$ the number of citations paper $i$ receives in year $t$ since publication, $r$ a particular subset of papers and $n_{t}$ the number of papers in $r$, this figure plots the evolution $\sum_{i \in r} c i t_{i, t} / n_{t}$ for successive values of $t$ as well as the evolution of the median values of these citations. Since we are analyzing articles published in a very short time window, "citation inflation" (Althouse et al., 2009; Anauati, Galiani, and Gálvez, 2016; Galiani and Gálvez, 2017, Neff and Olden, 2010), which refers to the observed common rise in citation counts over the years, is not relevant for comparison across articles, as all of them experienced the same inflation during this period.
} 
same time across journals tiers. For articles published in top five journals, a peak is reached around the fifteenth year after publication (being more than four times as high as the peak of articles published in second tier or field journals). ${ }^{4}$ On the other hand, for articles published in second tier and top field journals, peaks are reached before in time (seven years after publication for second tier journals and eight years after publication for top field journals). This suggests that articles published in top five journals do not only receive more citations, but also that citations are received for longer periods of time; i.e. the life cycles of their citations are longer.

\footnotetext{
${ }^{4}$ Note that Anauati, Galiani, and Gálvez (2016) finds that median papers published in top five journals reach their peak between three and five years after their publication. This differs from our results because Anauati, Galiani, \& Gálvez (2016) examine articles published in a rather longer time window (from 1970 to 2000) and take into account "citation inflation".
} 
Figure 1. Yearly Mean and Median Citations Received by across Journal Tiers and Fields of Economics Research
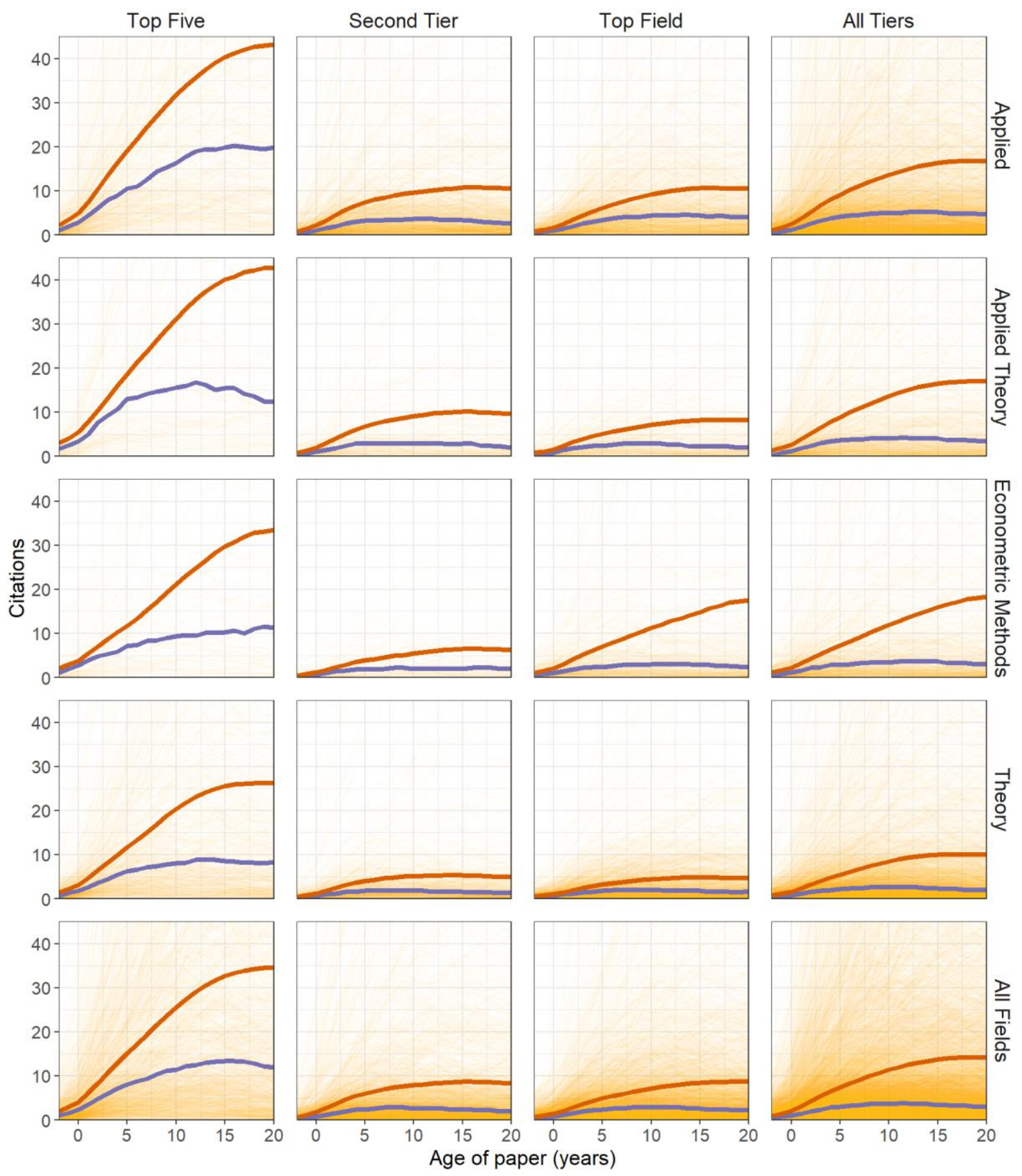

Median

Mean

Note: Mean and median citations are smoothed using five-year centered moving averages. Light orange lines show the trajectory of individual papers yearly citations. 
In line with previous research, Figure 1 also shows that, no matter the journal tier, citation patterns are more favorable for applied and applied theory papers than for theory and econometric methods papers (Figure S2 replicates Figure 1 but with free scales across panels for the $y$-axis and ignoring individual papers' trajectories). Concretely, they receive more citations per year, have a higher peak level, and receive more citations during their first years since publication. Nevertheless, when focusing on second tier and top field journals, median citations show less differences across fields of economics research than mean citations. This suggests that in these tiers heterogeneity among field of research may be mainly attributed to papers in the high end of the distribution. Econometric method papers are a special case. Their citation patterns in second-tier journals outperform slightly that of theoretical papers. However, they behave differently in top field journals depending on whether we observe the mean or median citation. When mean citations are used, citation patterns of this field exceeds that of applied and applied theory papers and resembles the behavior of econometric methods top five journals papers. Whereas, when the median is used, the performance of econometric method papers declines in relative terms compared to other fields. This suggests there are very successful econometric method papers that receive many citation counts. ${ }^{5}$

Individual trajectories of articles' yearly citations observed in Figure 1 suggest a great heterogeneity of success in terms of yearly citations across articles. To better focus in this phenomenon, Figure 2 plots the distribution of total citations received by papers across journals. One feature that arises from examining this figure is that the JEL and the JEP behave similarly, in terms of accumulated citations, to top five journals. It should be mentioned that these two journals have a high proportion of applied articles, specifically $57 \%$ and $82 \%$ in the JEL and the JEP respectively (See Figure A1). A second feature is that after excluding these two journals, top field journals slightly outperform second tier journals in terms of citations counts. This is reflected in that, for the former, total citations per article range from 0 to 8676, with a mean (median) of 136 (51) and 491 citations at the $95^{\text {th }}$ percentile, whereas, for the latter, total citations per article range from 0 to 5741, with a mean (median) of 114 (46) and 423 citations at the $95^{\text {th }}$ percentile. Finally, a third feature that arises from this figure is that less highly-cited articles in the top five journals, for instance those in the first decile of the distribution of citations, are widely outperformed by median articles in second tier and top field journals. This is in line with Oswald (2007) finding that the less highly-cited articles in the top journals are easily bettered by good articles in less prestigious outlets.

\footnotetext{
${ }^{5}$ Detailed inspection of the data shows that the tree most highly-cited econometric method articles in top field journals ended with 4631, 6313 and 8676 citations compared with 2627, 2876 and 5131 citations in top five journals.
} 
Figure 2. Distribution of Total Citations by Publication Venue
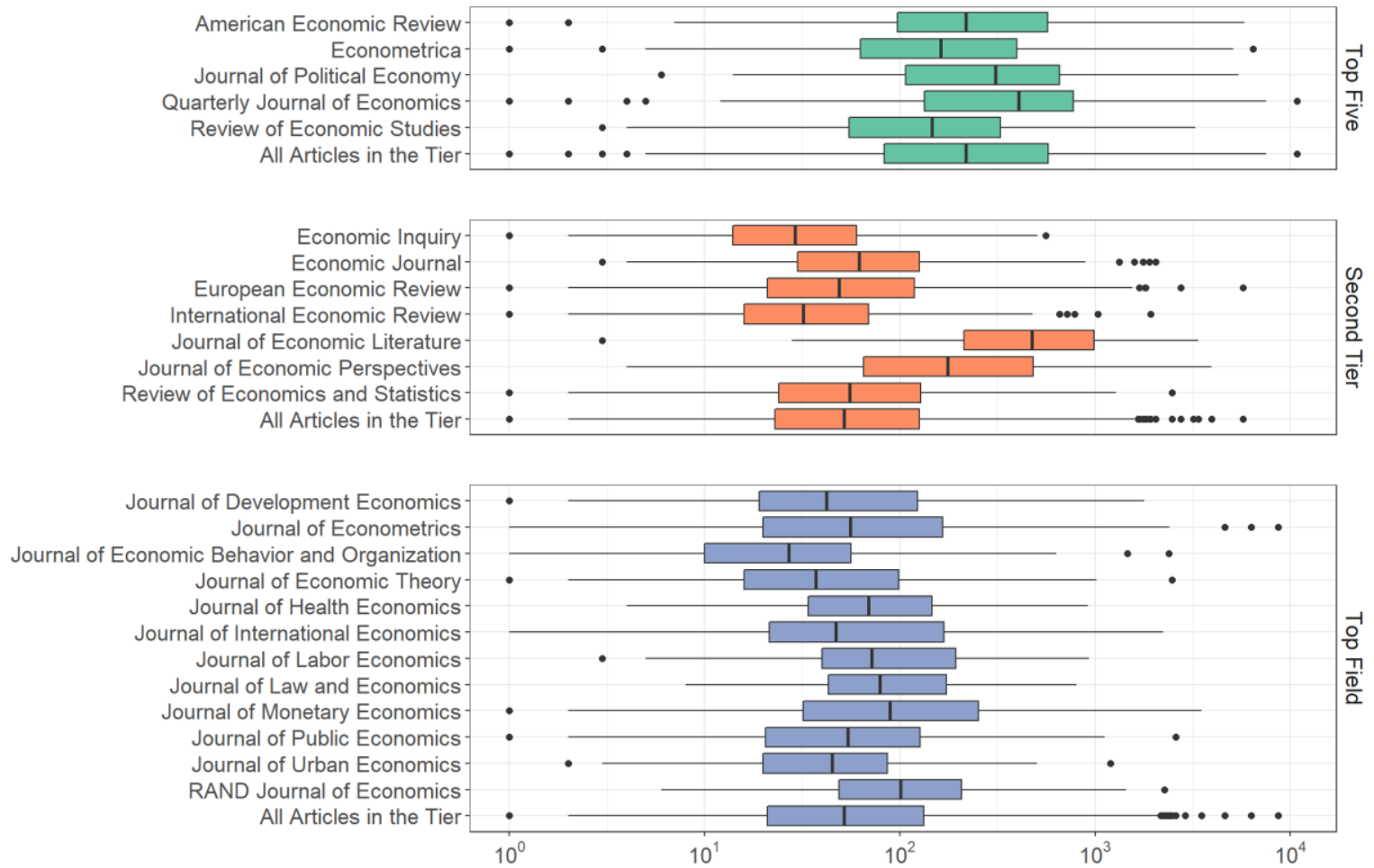

Note: 1 was added to the total citations of each article to avoid dropping articles with no citations when plotting in logarithmic scale.

Now we place our focus on total citation patterns across journals tiers and fields of economics research. Figure 3 shows empirical quantile functions of articles' total citations. As expected, for almost all quantiles, total citations received by papers in top five journals are higher than the ones received by papers published in non-top five journals. Moreover, the distribution of cites to top five papers stochastically dominates the distribution of citations for applied, applied theory and theory non-top five journals papers. However, in the case of econometric methods, the distribution of citations of field journals crosses the distribution of top five at nearly the $99.37^{\text {th }}$ percentile; pointing again toward the presence of very successful econometric methods articles published in top field journals that even outperform the most successful econometric methods articles published in top five journals. ${ }^{6}$

\footnotetext{
${ }^{6}$ From the inset graphs within each panel of Figure 3 it can be observed that applied, applied theory, theory and econometric methods papers in the first decile of the distribution of citations of top five journals have the same number of citations as articles in the 56th, 54th, 37th and 27th (55th, 53th, 37th and 28th) percentiles of the
} 
Figure 3. Empirical Quantile Functions of Articles' Total Citations across Journal Tiers and Fields of Economics Research
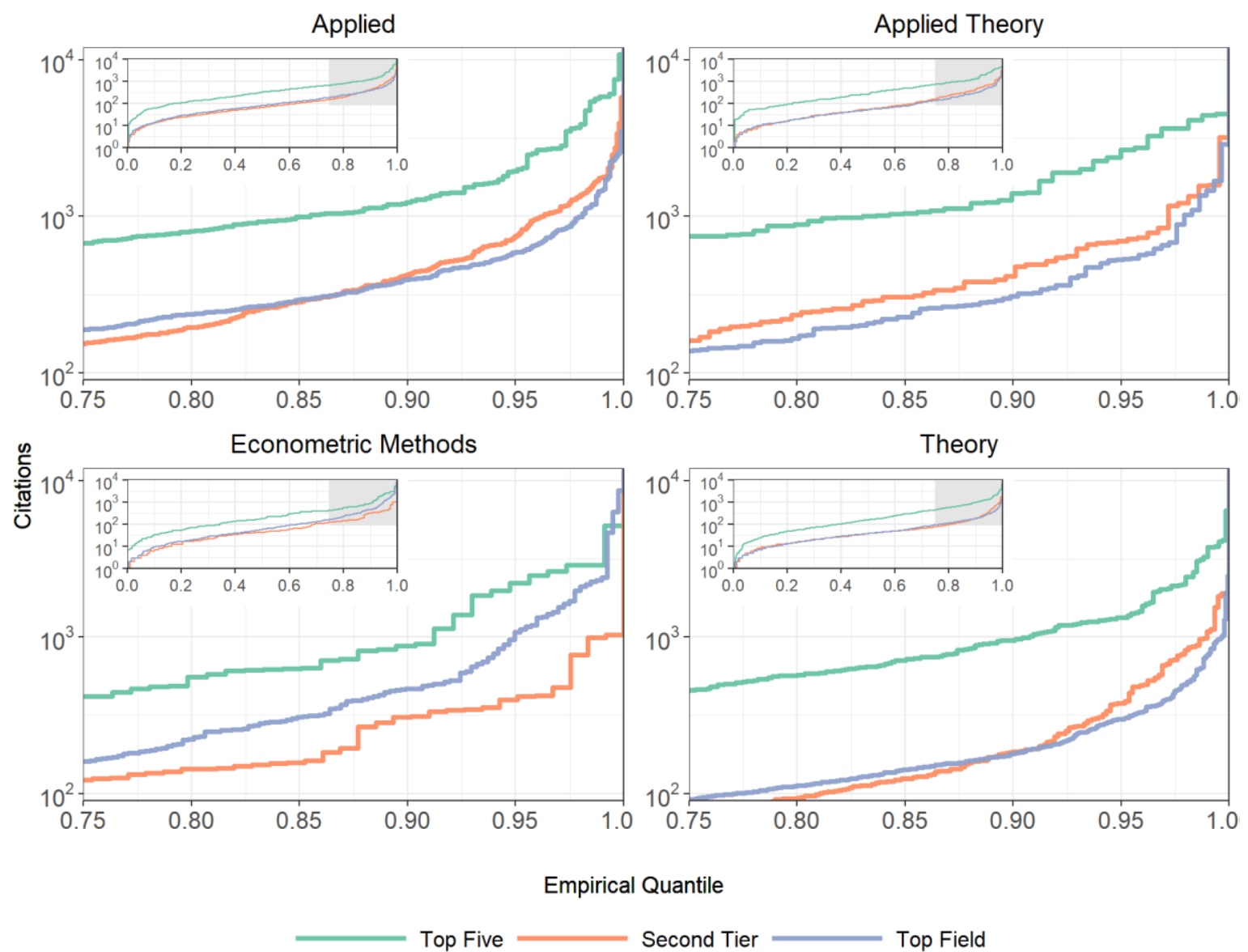

Note: 1 was added to the total citations of each article to avoid dropping articles with no citations when plotting in logarithmic scale.

Figure 3 also shows that, except for econometric method papers, second-tier and top field journals are similar in terms of citations' distribution. The cumulative distribution curve of top field journals is in general slightly above the curve of second tier journals until the $87^{\text {th }}$ and $90^{\text {th }}$ percentile in the cases of applied and theory papers respectively, where both curves intersect. In the case of applied theory papers, the curve of second tier journals is slightly above the curve of top field journals until the $99.5^{\text {th }}$ percentile where they intersect. Finally, the cumulative distribution curve of econometric

distribution of citations of second tier (top field) journals. This confirms the finding that less highly-cited articles in the top five journals are easily outperformed by median articles in second tier and top field journals. 
method papers in top field journals stochastically dominates the cumulative distribution curve of this type of articles in second-tier journals.

Figure 4. Percentage Difference of Empirical Quantile Functions of Articles Total Citations across Journal Tiers

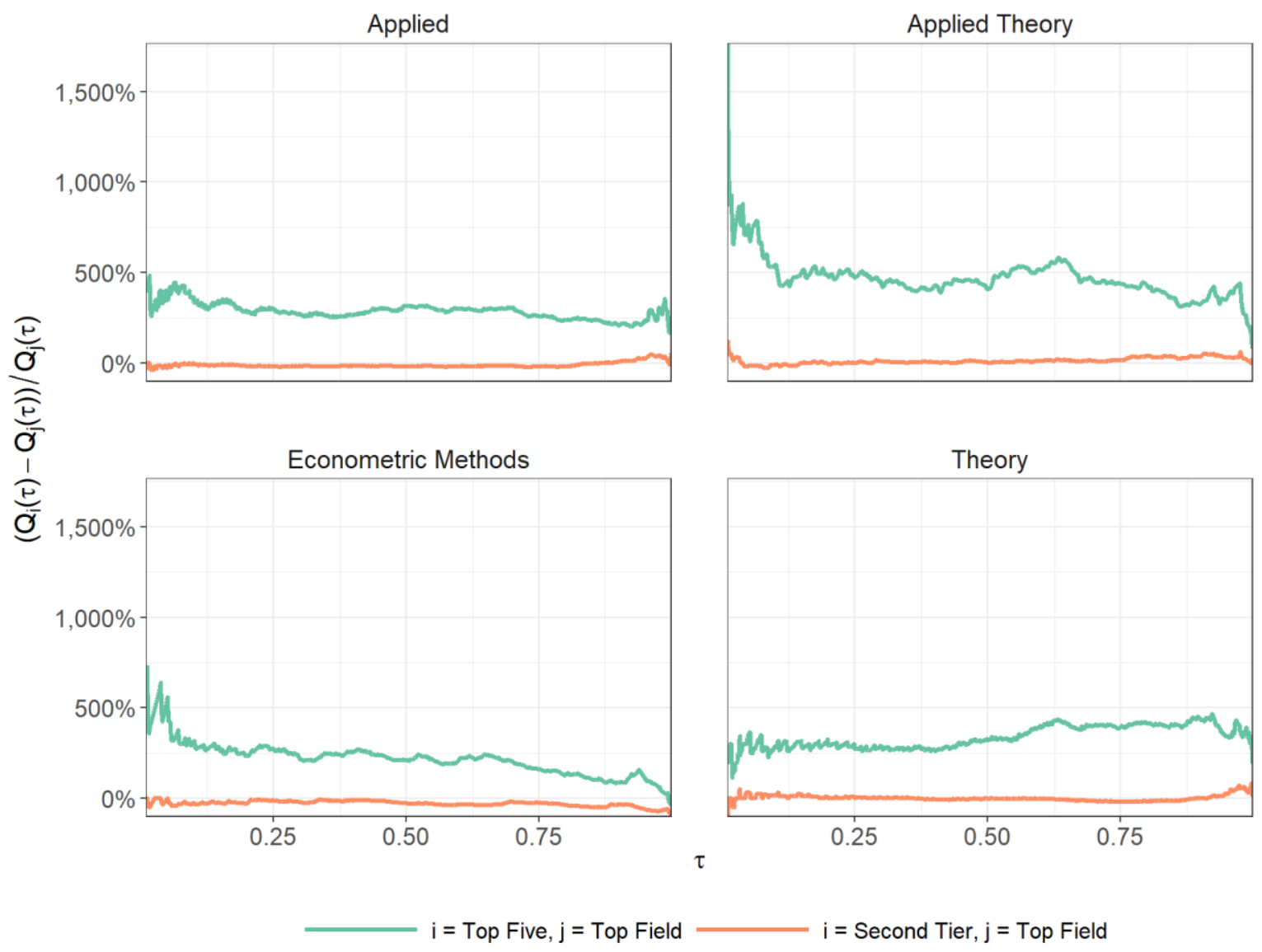

To avoid being misguided by the logarithmic scale used in Figure 3, Figure 4 plots percentage differences of total citations' empirical quantile functions across journal tiers (Table S2 details this data for a selected subset of empirical quantiles). For the sake of exposition, we now focus only on differences between articles published on top five and top field journals, since articles published in top field journals behave similarly to second tier journals the interpretation can be generalized to them. Figure 4 shows some interesting patterns. First, and before focusing in the differences across fields of economics research, during the first two decades after publication a top five journal article in the first tenth part of the distribution receives as many citations as those received by 3.83 (4.31) second tier (top field) journal articles in the same percentile; while a top five journal article in the last 
tenth part of the distribution receives as many citations as those received by 3.31 (3.76) second tier (top field) articles in the same percentile and over the same period (see Table S2). Second, in relative terms, the overall magnitude of the difference tends to be larger for applied theory papers and smaller for econometric methods papers, no matter the articles' success. Third, and more interesting, how these differences vary across articles' success differs greatly among fields of economics research. For applied articles, the gap narrows very mildly as one moves toward more successful articles, whereas this narrowing is sharp for the case of econometric methods papers (even converging at high values) and applied theory papers (which show a dramatic narrowing, but not strong enough as to attain convergence). Surprisingly, theory papers show and opposite pattern: the gap widens as one moves to highly successful papers. In other words, in all fields of economics research, except for theory, the more successful a top five article is, the relatively less successful it is when compared to an equivalent article published in non-top five venues; but, for theory papers, the opposite pattern is observed: successful top five articles are even relatively more successful when compared to non-top five ones.

Finally, Figure 4 also confirms the finding that top field journals behave relatively similarly in term of citations than second-tier journals. In this case, the difference moves around zero regardless the research field, which suggests that both type of journals present similar cumulative citation distributions. However, there are a few points to highlight. First, the difference is close to null for applied, applied theory and theory papers, except for the high percentiles, where it grows to a small extent. These patterns suggest that highly cited articles are slightly more successful in second tier journals than in top field ones. Second, the difference is negative and small for econometric methods articles; but it widens a bit more for highly successful articles.

\section{Discussion and conclusions}

As stated by Gibson (2014), economics is unusual among academic disciplines in the emphasis it places on publication in a narrow set of top journals. Given that publication venue reputation does not necessarily go hand in hand with citation performance, we study how citation patterns differ between three different journal tiers (top five, prestigious second tier, and top field journals).

The main result of this article is that citation patterns vary greatly across journal tiers. Our data suggest a series of clear-cut patterns. First, total citations received by a typical (as measured by mean and median citations) article published in a top five journal tend to be higher than the ones received by non-top five outlets. Second, and as one would expect, average and median yearly citations received by top five journal papers are higher than the ones second tier and top field journals papers received for every year since publication. Third, the life cycles of articles across journal tiers differ. Median 
articles published in non-top five journals reach a peak of yearly citations that is lower and earlier in time than that of top five journals. This suggests that top five journals' articles do not only receive more citations, but also that citations are received for longer periods of time; that is the life cycles of their citations is longer. Fourth, no matter the journal tier, citation patterns tend to be more favorable for applied and applied theory papers than for theory and econometric methods papers. They receive more citations per year and have a higher peak level. Fifth, there is a relative overlap in total citations; the less highly-cited articles in the top journals are easily bettered by median articles in less prestigious outlets. This goes in line with Hamermesh (2018), Stern (2013), and Oswald (2007) results. Sixth, when focusing on interactions between articles' success and fields of economics research, we find that the distribution of total citations of applied, applied theory, and theoretical top five publications stochastically dominate (i.e., total citations are higher, no matter the articles' success) than that of second-tier and top field journals papers. However, for econometric method papers, the distribution of total citations of field journals crosses the distribution of top five at the $99.37^{\text {th }}$ percentile. Seventh, in general, no matter the articles' success, the distribution of total citations of top field journals is in general slightly above that of second tier journals, and only for highly successful papers this reverts. In contrast, the distribution of econometric method papers in top field journals stochastically dominates that of second-tier journals. Eight, in general, a non-successful top five article receives little more than 4 times as many cites as an equivalently non-successful second tier or top field article; while a successful top five article receives around 3.5 times as many cites as an equivalently successful second tier of top field article. This suggests that, at least as measured by received citations, the statement that an article in a top five journal should be valorized more than five good publications outside these venues may be overestimated. Ninth, no matter the articles' success, in relative terms, the overall magnitude of the difference in citations received by articles published in top five journals against the ones received by articles published in second tier or top field journals tend to be larger for applied theory papers and smaller for econometric methods papers. Tenth, how relative differences vary across articles' success differs greatly across fields of economics research. For applied articles the gap narrows very mildly as one moves toward more successful articles, whereas this narrowing is sharp for the case of econometric methods papers (even converging at high values) and applied theory papers (which shows a dramatic narrowing, but not strong enough as to attain convergence). Notably, theory papers show and opposite pattern: the gap widens as one moves to highly successful papers. Eleventh, in general, top field journals behave relatively similar to second tier journals in term of citation patterns, being an exception econometric methods articles published in top field outlets. 
We believe the clear-cut facts reported in this article may help in the understanding of incentives behind important issues in economics (e.g., the direction of research in economics, the career paths of young researchers, the reputation and pay of economics scholars, inter alia); however, a few caveats must be mentioned regarding their scope. First, our results are purely descriptive and should not be interpolated as suggesting that the same paper will receive more citations simply because it was published in a top tier journal relative to a scenario where it was published in a non-top tier prestigious outlet. The dynamics behind citations are quite more complex than this. Take the following example: as economics scholars prioritize publishing in top five journals, competition is stronger in those journals, and selection arises. ${ }^{7}$ For this reason, one would expect stronger and more innovative papers to be published in top five journals, and, as one would also expect stronger papers to be cited more, this should translate into articles published in top five journals having higher citation counts. However, for the same reason, one could also expect some top tier papers to be cited more simply because they were published in these venues. Concretely, if authors search more extensively previous literature in top tier journals (something expected if articles published in these journals are regarded as stronger), cites may simply flow toward an article published in these outlets because of their reputation, something an equivalent-in-quality article published in a non-top tier venue may not benefit from. Identifying, disentangling and quantifying the magnitude of these type of effects remains as an open research question. Second, given that right from the beginning we planned to study differences in yearly citation patterns for long periods, our analysis focuses on articles published more than twenty years ago (and their present day received citations). This means that patterns for present day articles may have changed. In fact, the literature suggests that factors that may affect citations patterns (e.g., acceptance rates) have effectively changed in the last decades (see, for example, Card and DellaVigna, 2013; Cherkashin et al., 2009). Given that evidence points toward competition being stronger in top tier journals, assuming the patterns reported in this article have deepened does not seem to be a longshot. Future research should focus in analyzing these patterns for newer articles.

\footnotetext{
7 According to Card and DellaVigna (2013), QJE had an acceptance rate of around 3\% by 2013, while, according to Cherkashin et al. (2009), the acceptance rate of the Journal of International Economics was around $14 \%$ by 2004.
} 


\section{References}

Althouse, Benjamin. M., Jevin D. West, Carl T. Bergstrom and Theodore Bergstrom. "Differences in impact factor across fields and over time." Journal of the Association for Information Science and Technology 60, no.1 (2009): 27-34.

Anauati, Victoria, Sebastian Galiani and Ramiro H. Gálvez. "Quantifying the life cycle of scholarly articles across fields of economic research.” Economic Inquiry 54, no.2 (2016): 1339-1355.

Card, David, and Stefano DellaVigna. "Nine facts about top journals in economics." Journal of Economic Literature 51, no.1 (2013): 144-161.

Cherkashin, Ivan, Svetlana Demidova, Susumu Imai and Kala Krishna. "The inside scoop: Acceptance and rejection at the journal of international economics." Journal of International Economics 77, (2009): 120-132.

Chiappori, Pierre-André, and Steven D. Levitt. "An examination of the influence of theory and individual theorists on empirical research in microeconomics." The American Economic Review 93, (2003): 151-155.

Coe, Robert K., and Irwin Weinstock. "Editorial Policies of the Major Economics Journals." Quarterly Review of Economics and Business 7, no.4 (1967): 37-43.

Cole, Stephen, and Jonathan R. Cole. "Scientific output and recognition - study in operation of reward system in science.” American Sociological Review 32, (1967): 377-390.

Ellison, Gleen. "How does the market use citation data? The Hirsch Index in economics." American Economic Journal: Applied Economics 5, no.3 (2013): 63-90.

Ellison, Glenn. "The Slowdown of the Economics Publishing Process." Journal of Political Economy 110, (2002): 947-993.

Galiani, Sebastian, and Ramiro Gálvez (2017). "The life cycle of scholarly articles across fields of research.” NBER Working Paper 23447, National Bureau of Economic Research, Cambridge, MA.

Gibson, John, David L. Anderson and John Tressler. "Which journal rankings best explain academic salaries? Evidence from the University of California." Economic Inquiry 52, no.4 (2014): 1322-1340.

Gibson, John, David L. Anderson, and John Tressler. "Citations or Journal Quality: Which is Rewarded More in the Academic Labor Market?." Economic Inquiry 55, no. 4 (2017): 1945-1965.

Gibson, John. "No top fives, no worries?" VoxEU.org. June 6, 2014. https://voxeu.org/article/no-topfives-no-worries (accessed September 18, 2018).

Hamermesh, Daniel S. "Citations in Economics: Measurement, Uses, and Impacts." Journal of Economic Literature 56, no.1 (2018): 115-56. 
Hamermesh, Daniel S., and Gerard A. Pfann. "Reputation and earnings: the roles of quality and quantity in academe." Economic Inquiry 50, no.1 (2012): 1-16.

Hazelkorn, Ellen. Rankings and the reshaping of higher education: The battle for world-class excellence. New York Palgrave Macmillan, 2011.

Hilmer, Christiana E., and Michael J. Hilmer. "How do journal quality, co-authorship, and author order affect agricultural economists' salaries?." American Journal of Agricultural Economics 87, no. 2 (2005): 509-523.

Hilmer, Michael J., Michael R. Ransom and Christiana E. Hilmer. "Fame and the fortune of academic economists: How the market rewards influential research in economics." Southern Economic Journal 82, no.2 (2015): 430-452.

James J. Heckman, and Sidharth Moktan. 2017. "Publishing and Promotion in Economics: The Curse of the Top Five". Paper presented at the American economic association annual meeting, Chicago.

Laband, David N. "Is there value-added from the review process in economics?: Preliminary evidence from authors." The Quarterly Journal of Economics 105, no.2 (1990): 341-352.

McKenzie, David. "Is the Impact Evaluation production function O-ring or a Knowledge Hierarchy?" Development Impact. April 7, 2014. https://blogs.worldbank.org/impactevaluations/impactevaluation-production-function-o-ring-or-knowledge-hierarchy (accessed September 18, 2018).

Neff, Bryan D., and Julian D. Olden. "Not so fast: inflation in impact factors contributes to apparent improvements in journal quality." BioScience 60, no.6 (2010): 455-459.

Oswald, Andrew J. "An examination of the reliability of prestigious scholarly journals: evidence and implications for decision-makers.” Economica 74, no.293 (2007): 21-31.

Serrano, Roberto. 2018. "Top5itis”. http://www.econ.brown.edu/Faculty/serrano/pdfs/wp2018-2Top5itis.pdf

Smith, Andy T., and Michael Eysenck. 2002. "The correlation between RAE ratings and citation counts in psychology". http://cogprints.org/2749/

Stern, David I. "Uncertainty measures for economics journal impact factors." Journal of Economic Literature 51, no.1 (2013): 173-89.

Trivedi, Pravin K. "An analysis of publication lags in econometrics." Journal of Applied Econometrics 8, no.1 (1993): 93-100.

Verma, Inder M. "Impact, Not Impact Factor." Proceedings of the National Academy of Sciences 112, no.26 (2015): 7875-76.

Yohe, Gary W. "Current publication lags in economics journals." Journal of Economic Literature 18, no.3 (1980): 1050-1055.. 
Zimmermann, Christian. “Academic rankings with RePEc.” Econometrics 1, no.3 (2013): 249-280. 


\section{Online Appendix}

Figure S1. Distribution of Fields of Economics Research across Journals and Journal Tiers

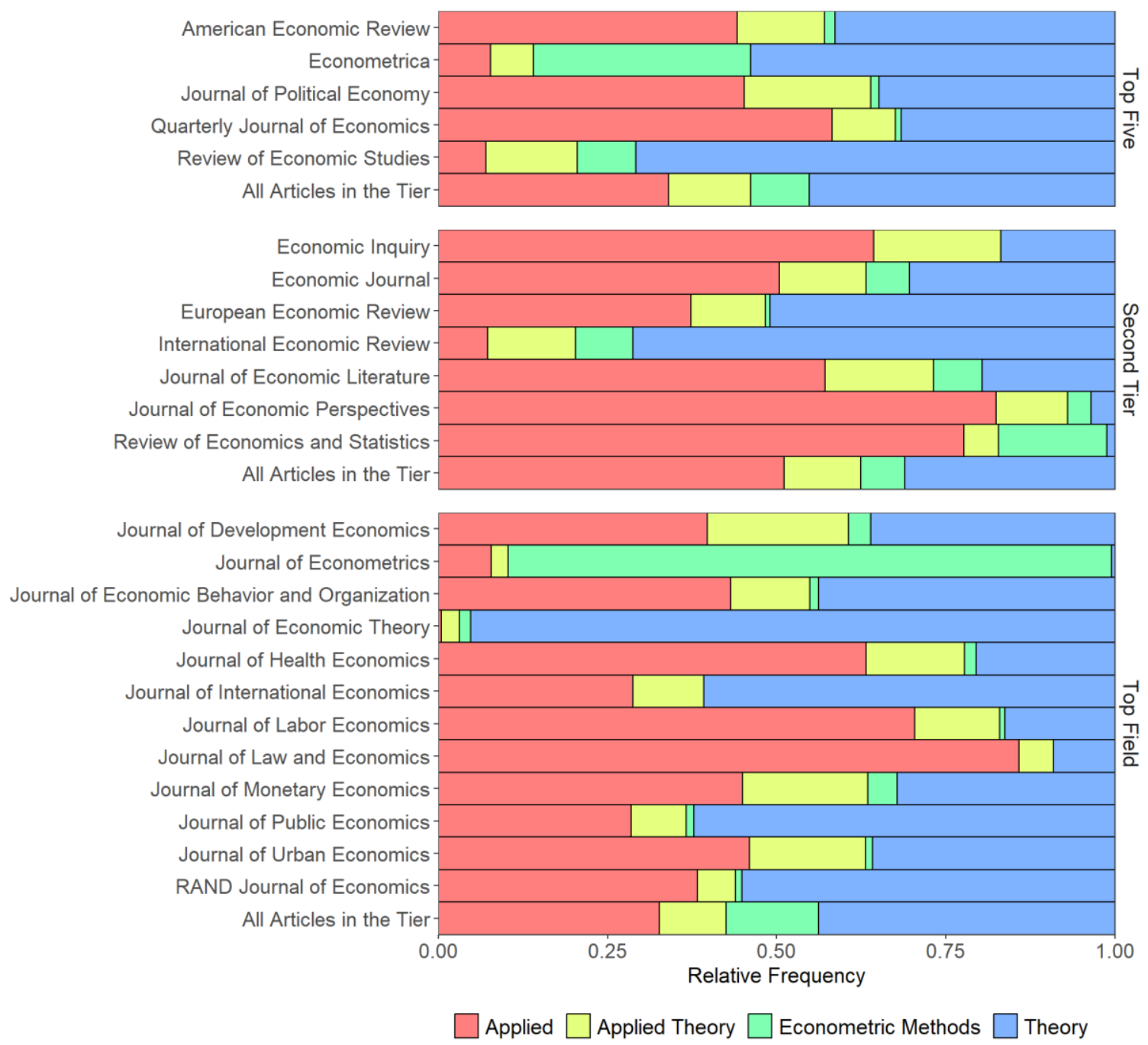


Figure S2. Yearly Mean and Median Citations Received by across Journal Tiers and Fields of Economics Research (Free $y$-axis)
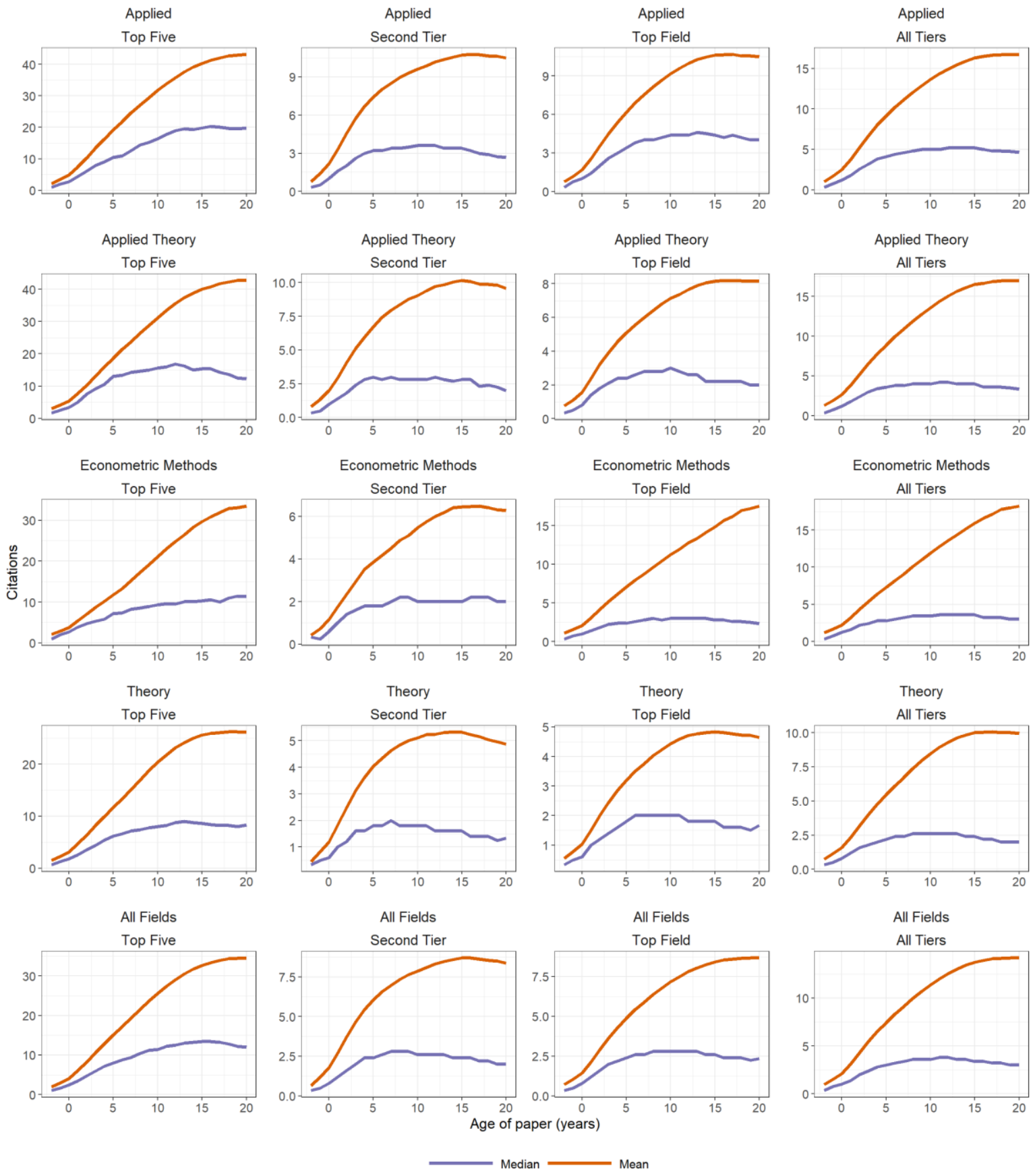
Table S1. Summary Statistics of Total Citation at the Article Level across Journals

\begin{tabular}{|c|c|c|c|c|c|c|c|c|c|}
\hline Journal & $\begin{array}{c}\text { Percentil } \\
0.05 \\
\end{array}$ & Median & $\begin{array}{c}\text { Percentil } \\
0.75 \\
\end{array}$ & $\begin{array}{c}\text { Percentil } \\
0.95 \\
\end{array}$ & Mean & S.D. & $\begin{array}{l}\text { Most } \\
\text { cited }\end{array}$ & $\begin{array}{c}\text { Total } \\
\text { citations }\end{array}$ & $\begin{array}{c}\mathrm{N}^{\circ} \text { of } \\
\text { Articles }\end{array}$ \\
\hline American Economic Review & 20.00 & 216.50 & 571.00 & $1,416.40$ & 466.79 & 704.95 & 5,799 & 183,917 & 394 \\
\hline Econometrica & 16.00 & 161.00 & 396.00 & $1,893.00$ & 403.45 & 757.86 & 6,418 & 109,336 & 271 \\
\hline Economic Inquiry & 3.90 & 28.00 & 59.00 & 155.30 & 52.53 & 75.60 & 557 & 11,505 & 219 \\
\hline Economic Journal & 8.00 & 61.00 & 125.00 & 493.70 & 135.44 & 241.70 & 2,037 & 48,624 & 359 \\
\hline European Economic Review & 4.00 & 48.00 & 117.50 & 524.20 & 137.88 & 376.42 & 5,741 & 61,633 & 447 \\
\hline International Economic Review & 3.00 & 31.00 & 68.00 & 284.00 & 75.21 & 164.53 & 1,921 & 19,631 & 261 \\
\hline Journal of Development Economics & 5.00 & 41.00 & 122.00 & 615.80 & 135.76 & 254.18 & 1,786 & 36,520 & 269 \\
\hline Journal of Econometrics & 3.00 & 55.00 & 165.00 & 901.90 & 227.47 & 669.10 & 8,676 & 90,762 & 399 \\
\hline Journal of Economic Behavior and Organization & 2.00 & 26.00 & 55.25 & 195.00 & 61.54 & 174.31 & 2,393 & 18,955 & 308 \\
\hline Journal of Economic Literature & 62.00 & 475.50 & 986.00 & $1,780.50$ & 670.04 & 639.32 & 3,387 & 37,522 & 56 \\
\hline Journal of Economic Perspectives & 17.60 & 174.50 & 481.25 & $1,189.10$ & 386.56 & 561.96 & 3,962 & 44,068 & 114 \\
\hline Journal of Economic Theory & 4.00 & 36.00 & 97.75 & 314.50 & 85.69 & 167.97 & 2,467 & 35,646 & 416 \\
\hline Journal of Health Economics & 10.80 & 68.00 & 145.00 & 318.20 & 111.97 & 127.78 & 917 & 13,100 & 117 \\
\hline Journal of International Economics & 6.00 & 46.00 & 168.00 & 620.00 & 156.98 & 281.66 & 2,230 & 29,983 & 191 \\
\hline Journal of Labor Economics & 14.70 & 71.00 & 193.00 & 457.70 & 145.69 & 171.87 & 928 & 19,668 & 135 \\
\hline Journal of Law and Economics & 18.00 & 78.00 & 172.00 & 472.30 & 133.12 & 147.03 & 803 & 13,179 & 99 \\
\hline Journal of Monetary Economics & 7.30 & 88.00 & 252.00 & 803.70 & 223.30 & 427.80 & 3,504 & 50,690 & 227 \\
\hline Journal of Political Economy & 25.00 & 309.00 & 657.00 & $1,618.00$ & 527.70 & 700.75 & 5,427 & 127,175 & 241 \\
\hline Journal of Public Economics & 5.00 & 53.00 & 126.00 & 288.40 & 101.52 & 187.50 & 2,594 & 36,038 & 355 \\
\hline Journal of Urban Economics & 5.30 & 44.00 & 85.50 & 200.80 & 73.55 & 113.23 & 1,198 & 13,754 & 187 \\
\hline Quarterly Journal of Economics & 25.80 & 404.00 & 775.00 & $2,795.60$ & 736.79 & $1,235.17$ & 10,836 & 165,777 & 225 \\
\hline RAND Journal of Economics & 16.75 & 100.00 & 206.25 & 542.75 & 176.76 & 247.45 & 2,265 & 34,644 & 196 \\
\hline Review of Economic Studies & 14.20 & 145.00 & 326.00 & $1,344.40$ & 321.49 & 516.79 & 3,262 & 59,476 & 185 \\
\hline Review of Economics and Statistics & 5.00 & 54.50 & 126.50 & 483.50 & 125.51 & 223.25 & 2,484 & 51,711 & 412 \\
\hline
\end{tabular}


Table S2. Detailed Percentage Difference of Empirical Quantile Functions of Articles Total Citations across Journal Tiers

\begin{tabular}{|c|c|c|c|c|c|c|c|c|c|c|}
\hline \multirow{2}{*}{$\begin{array}{l}\text { Empirical } \\
\text { Quantile }\end{array}$} & \multicolumn{5}{|c|}{ Top Five / Second Tier } & \multicolumn{5}{|c|}{ Top Five / Top Field } \\
\hline & $\begin{array}{l}\text { All } \\
\text { tiers }\end{array}$ & Applied & Applied theory & $\begin{array}{c}\text { Econometric } \\
\text { methods }\end{array}$ & Theory & $\begin{array}{l}\text { All } \\
\text { tiers }\end{array}$ & Applied & Applied theory & $\begin{array}{c}\text { Econometric } \\
\text { methods }\end{array}$ & Theory \\
\hline 0.1 & 2.83 & 3.67 & 6.14 & 4.55 & 2.29 & 3.31 & 3.50 & 5.42 & 3.16 & 2.83 \\
\hline 0.2 & 2.76 & 3.61 & 5.13 & 3.54 & 2.92 & 3.00 & 2.79 & 4.75 & 2.35 & 2.92 \\
\hline 0.3 & 2.88 & 3.38 & 3.92 & 3.05 & 2.68 & 2.88 & 2.73 & 4.37 & 2.17 & 2.89 \\
\hline 0.4 & 2.94 & 3.32 & 4.01 & 3.05 & 2.87 & 3.14 & 2.65 & 4.28 & 2.56 & 2.64 \\
\hline 0.5 & 3.25 & 4.03 & 3.93 & 3.29 & 3.33 & 3.25 & 3.15 & 4.07 & 2.12 & 3.22 \\
\hline 0.6 & 3.84 & 3.83 & 4.40 & 3.78 & 4.01 & 3.53 & 3.00 & 5.16 & 2.18 & 3.97 \\
\hline 0.7 & 3.60 & 3.74 & 3.95 & 2.76 & 4.97 & 3.38 & 3.07 & 4.50 & 2.05 & 4.01 \\
\hline 0.8 & 3.30 & 3.11 & 2.80 & 2.64 & 5.17 & 3.19 & 2.38 & 4.30 & 1.33 & 4.16 \\
\hline 0.9 & 2.31 & 1.88 & 2.14 & 1.85 & 4.23 & 2.76 & 2.08 & 3.27 & 0.87 & 4.35 \\
\hline
\end{tabular}

